\title{
Effect of Formulated Ingredients on Rapidly Disintegrating Oral Tablets Prepared by the Crystalline Transition Method
}

\author{
Masaaki Sugimoto, ${ }^{*}, a$ Shinji Narisawa, ${ }^{a}$ Koji Matsubara, ${ }^{a}$ Hiroyuki Yoshino, ${ }^{a}$ \\ Minoru NAKANO, ${ }^{b}$ and Tetsurou $\mathrm{HANDA}^{b}$ \\ ${ }^{a}$ Pharmaceutical Development Laboratories, Tanabe Seiyaku Co., Ltd.; 3-16-89 Kashima, Yodogawa-ku, Osaka \\ 532-8505, Japan: and ${ }^{b}$ Graduate School of Pharmaceutical Sciences, Kyoto University; Sakyo-ku, Kyoto 606-8501, \\ Japan. Received August 12, 2005; accepted November 19, 2005
}

The aim of this article was to determine the optimal ingredients for the rapidly disintegrating oral tablets prepared by the crystalline transition method (CT method). The effect of ingredients (diluent, active drug substance and amorphous sugar) on the characteristics of the tablets was investigated. The ingredients were compressed and the resultant tablets were stored under various conditions. The oral disintegration time of the tablet significantly depended on diluents, due to differences in the penetration of a small amount of water in the mouth and the viscous area formed inside the tablet. The oral disintegration time was $10-30 \mathrm{~s}$ for tablets with a tensile strength of approximately $1 \mathrm{MPa}$, when erythritol, mannitol or xylitol was used as the diluent. The increase in the tensile strength of tablets containing highly water-soluble active drug substances during storage was as large as that of tablets without active drug substances, while the increase in the tensile strength of tablets containing low water-soluble active drug substances was small. It was therefore found that highly water-soluble active drug substances were more suitable for the formulation prepared by the CT method than low water-soluble active drug substances. Irrespective of the type of amorphous sugar (amorphous sucrose, lactose or maltose) used, the porosity of tablets with $1 \mathrm{MPa}$ of tensile strength was $30-40 \%$, and their oral disintegration time was $10-20 \mathrm{~s}$. The optimal ingredients for rapidly disintegrating oral tablets with reasonable tensile strength and disintegration time were therefore determined from these results.

Key words rapidly disintegrating oral tablet; amorphous sugar; tensile strength; porosity; ingredient

Many studies have focused on the ingredients suitable for rapidly disintegrating oral tablets ${ }^{1-5)}$ that contain disintegrants, such as microcrystalline cellulose or low substituted hydroxypropylcellulose. However, the main disadvantage of these tablets is a rough feeling in the mouth, because they are water-insoluble. To solve this problem, we used water-soluble sugars as ingredients of rapidly disintegrating oral tablets and developed a preparation method, the Crystalline Transition Method (CT method), as a promising protocol to improve medication compliance. ${ }^{6}$

The CT method is a method utilizing the crystalline transition of amorphous sugars. The choice of amorphous sugar is therefore a critical factor for the CT method, because each amorphous sugar has a different glass transition temperature $(\mathrm{Tg}),{ }^{7)}$ with a distinct amount of water absorbed under any given humidity and temperature. ${ }^{8)}$ In addition, the formulated diluents and active drug substances, which are main components of these tablets, were anticipated to greatly influence the characteristics, i.e. tensile strength, porosity and oral disintegration time.

In this study, the effects of formulated ingredients (diluent, active drug substance and amorphous sugar) on the characteristics of rapidly disintegrating oral tablets were investigated in detail. The aim of this study was to determine the optimal ingredients for rapidly disintegrating oral tablets prepared by the CT method.

\section{Experimental}

Materials As model drugs, three active drug substances with different water solubility were chosen. Nicotinic acid amide (NA) (Yuki Gosei Co., Ltd., Japan), diltiazem hydrochloride (DH) (Tanabe Seiyaku Co., Ltd., Japan) and bisbentiamine (BB) (Tanabe Seiyaku Co., Ltd., Japan) were all of JP grade. All model drugs were passed through a 200 -mesh sieve $(75 \mu \mathrm{m})$ before use.
D-mannitol (Kyowa Hakko Co., Ltd., Japan), erythritol (Nikken Chemical Co., Ltd., Japan), xylitol (Towa Kasei Co., Ltd., Japan), glucose (Nippon Shokuhinkako Co., Ltd., Japan) and d-sorbitol (Towa Kasei Co., Ltd., Japan) were used as diluents. These diluents were also passed through a 200-mesh sieve $(75 \mu \mathrm{m})$ before use. To study the effect of particle size, $\alpha$-lactose monohydrate (DMV International, Netherlands) was sieved using a Turbo Screener (Turbo Kogyo Co., Ltd., Japan) to separate into the following three fractions: $75-100 \mu \mathrm{m}, 150-180 \mu \mathrm{m}$ and $250-300 \mu \mathrm{m}$. Amorphous sugars were prepared by freeze-drying sucrose (Taito Co., Ltd., Japan), $\alpha$-lactose monohydrate and maltose monohydrate (Hayashibara Co., Ltd., Japan) aqueous solutions. Ingredients other than erythritol and maltose monohydrate were of JP grade. Erythritol and maltose monohydrate were of JPE grade

Preparation of Amorphous Sugars A 5\% (w/v) solution was prepared by dissolving each sugar in water. The solution was placed on a shelf in a vacuum freeze-dryer (RL-100BS, Kyowa, Japan) and frozen at $-50{ }^{\circ} \mathrm{C}$ for $5 \mathrm{~h}$. Primary and secondary drying were performed at $0^{\circ} \mathrm{C}$ (shelf temp.) for $40 \mathrm{~h}$, and $40^{\circ} \mathrm{C}$ (shelf temp.) for $20 \mathrm{~h}$, respectively.

Preparation of Compression Mixtures An amorphous sugar and diluent at various weight ratios, with or without an active drug substance, were mixed by shaking in a plastic bag. After shaking, the mixtures were sieved through a $500 \mu \mathrm{m}$ screen to ensure homogeneity.

Compressing Each sample was compressed into flat tablets of $10 \mathrm{~mm}$ diameter using a rotary tabletting machine (F-9, Kikusui Seisakusho, Japan) at compression forces from 10 to $150 \mathrm{MPa}$ at a rotation speed of $20 \mathrm{rpm}$. The punches and dies were lubricated with a small amount of magnesium stearate using a cotton swab before compression.

Storage of Tablets under Various Humidity Conditions The tablets were stored at $25^{\circ} \mathrm{C}$ in desiccators over saturated salt solutions to provide constant conditions of relative humidity. Different humidity conditions were adopted depending on the different Tg values of each amorphous sugar used (sucrose: $34 \%$ relative humidity, lactose: $51 \%$ relative humidity, maltose: $75 \%$ relative humidity). The relative humidity conditions of approximately 34,51 , and $75 \%$ were controlled by using salt solutions of magnesium chloride hexahydrate, calcium nitrate tetrahydrate, and sodium chloride, respectively.

Measurement of Tablet Tensile Strength The tablet crushing load $(F)$, which is the force required to break a tablet by diametral compression, was measured using a tablet hardness tester (Tablet Tester 6D, SCHLEUNIGER, Germany). The tensile strength $(T)$ was calculated using the following equa- 

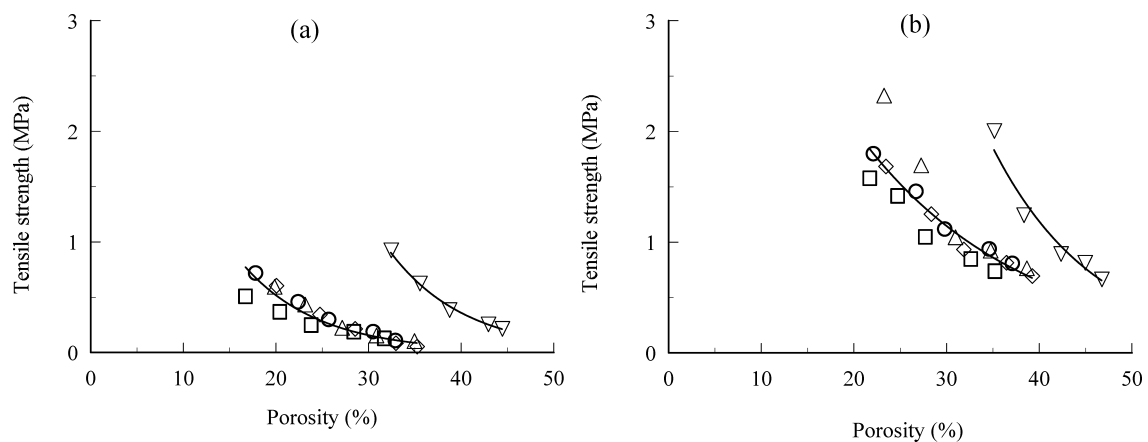

Fig. 1. Change in Tensile Strength of Tablets Comprised of Different Diluents

$\square$, erythritol; $\bigcirc$, mannitol; $\triangle$, xylitol; $\diamond$, glucose; $\nabla$, sorbitol. Tensile strength of tablets with $20 \%$ of amorphous sucrose before (a) and after (b) storage at $25^{\circ} \mathrm{C}$ under $34 \%$ relative humidity was measured.

tion:

$$
T(\mathrm{MPa})=\frac{2 F}{\pi D H} \times \frac{1}{1000}
$$

Where $F(\mathrm{~N})$ is the crushing load, and $D(\mathrm{~cm})$ and $H(\mathrm{~cm})$ are the diameter and thickness of the tablet, respectively. The data given are the means of at least 5 measurements.

Measurement of Tablet Porosity The porosity of the tablet $(\varepsilon)$ was calculated using the following equation:

$$
\varepsilon(\%)=\left(1-\frac{M}{V \rho}\right) \times 100
$$

Where $M(\mathrm{~g})$ is the tablet weight, $V\left(\mathrm{~cm}^{3}\right)$ is the tablet volume and $\rho$ $\left(\mathrm{g} / \mathrm{cm}^{3}\right)$ is true density of powders. The tablet volume was calculated from the diameter and thickness of the tablet measured with a micrometer. The true density of powder was determined using a pycnometer (autopycnometer type: 1320 , Micromeritics, U.S.A.).

Measurement of Oral Disintegration Time The time required for complete oral disintegration was measured using five healthy volunteers. The end point of oral disintegration was when a tablet placed on the tongue had disintegrated until no lumps remained. The volunteers did not move their tongue during the test. ${ }^{6}$

Measurement of Viscosity An aqueous solution of each diluent was prepared. The concentration of each solution was different, because each diluent has different solubility in water. Each solution was then diluted to various concentration levels. The viscosity of each aqueous solution was measured at $25^{\circ} \mathrm{C}$ using a digital viscometer (Type DV, TOKIMEC Inc.) of a No. 1 or No. 2 spindle. The rotation speed of the spindle was set at $60 \mathrm{rpm}$. Viscosity corresponding to $100 \%$ concentration of diluent $\left(\eta_{c=100 \%}\right)$ was calculated by extrapolating the measured viscosity when plotted against the diluent concentration in the solution.

Moisture Absorption Moisture absorption isotherm for each diluent was determined gravimetrically at $25^{\circ} \mathrm{C}$. Each sample of approximately $2 \mathrm{~g}$ was placed in a glass vial and stored in a desiccator over saturated salt solution to provide constant relative humidity condition until the constant weight was obtained. The relative humidity conditions of approximately $22,34,51$, 75 , and $84 \%$ were controlled by using salt solutions of potassium acetate, magnesium chloride hexahydrate, calcium nitrate tetrahydrate, sodium chloride, and potassium chloride, respectively. Then, the sample was dried at $60^{\circ} \mathrm{C}$ for $3 \mathrm{~h}$ under reduced pressure. The moisture content of the sample was calculated as the loss on drying.

Powder X-Ray Diffraction Measurement The powder X-ray diffraction patterns were measured at room temperature with an X-ray diffractometer (M03X-HF, MAC Science, Japan). The measurement conditions were as follows: target, $\mathrm{Cu}$; filter, $\mathrm{Ni}$; voltage, $40 \mathrm{kV}$; current, $35 \mathrm{~mA}$; and scanning speed, $4 \% \mathrm{~min}$

\section{Results and Discussion}

Effect of Diluent on Rapidly Disintegrating Oral Tablets We found that the tensile strength of tablets consisting of $80 \%$ of mannitol and $20 \%$ of amorphous sucrose remarkably increased after amorphous sucrose crystalliza-

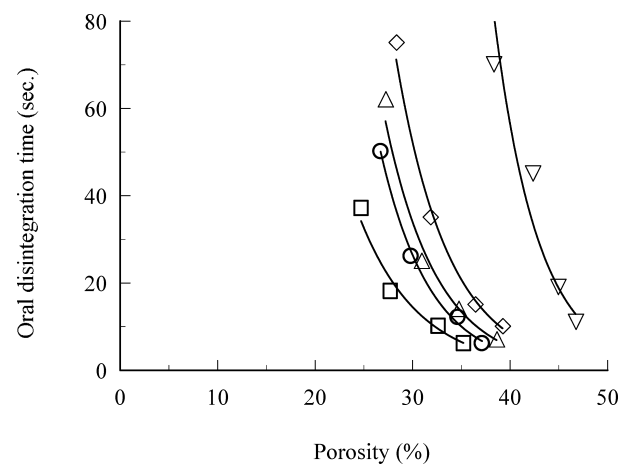

Fig. 2. Relationship between Oral Disintegration Time and Porosity of Tablets

$\square$, erythritol; $\bigcirc$, mannitol; $\triangle$, xylitol; $\diamond$, glucose; $\nabla$, sorbitol. Oral disintegration time of tablets comprised of different diluents with $20 \%$ of amorphous sucrose after storage at $25^{\circ} \mathrm{C}$ under $34 \%$ relative humidity was measured.

tion, and this methodology was used to prepare rapidly disintegrating oral tablets. ${ }^{6}$ In this study, we investigated the effect of diluents other than mannitol on tablet characteristics. The tablets comprised of different diluents and $20 \%$ of amorphous sucrose were stored at $25^{\circ} \mathrm{C}$ under $34 \%$ relative humidity for $5 \mathrm{~d}$. Figure 1 shows the change in tensile strength of the tablets during storage. The tensile strength increased during storage, and the degree of increase was found to be similar within the porosity range examined, irrespective of the kind of diluent used. In a previous paper, we showed the formation of new internal contact points in tablets comprised of mannitol and amorphous sucrose and the increase in tablet tensile strength by amorphous sucrose crystallization during storage. ${ }^{6}$ This result therefore shows that the increase in tensile strength depends on amorphous sucrose crystallization, irrespective of the diluent.

The effect of diluents on the oral disintegration time is shown in Fig. 2. Higher porosity tablets had a faster disintegration time, irrespective of the diluent used. In addition, it was observed that the diluent considerably affected the disintegration time, even if the tablet porosities were comparable. The disintegration time was shortest for tablets containing erythritol followed by mannitol, xylitol, glucose, and sorbitol.

It is well known that the disintegration time of a tablet is related to the water penetration rate into the powder beds. ${ }^{9,10)}$ Furthermore, Oshima et al. studied the relationship between the disintegration time and water penetrating rate of rapidly disintegrating tablets in the oral cavity, and concluded that a 
Table 1. Relationship between Viscosity of Diluent and Oral Disintegration Time of Tablet Comprised of the Different Diluent with 20\% of Amorphous Sucrose after Storage

\begin{tabular}{lcc}
\hline \hline Diluent & $\begin{array}{c}\text { Viscosity }\left(\eta_{c=100 \%}\right)^{a)} \\
(\mathrm{mPa} \cdot \mathrm{s})\end{array}$ & $\begin{array}{c}\text { Oral disintegration time } \\
(\mathrm{s})\end{array}$ \\
\hline Erythritol & 54 & 6 \\
Mannitol & 158 & 10 \\
Xylitol & 233 & 14 \\
Glucose & 1581 & 21 \\
Sorbitol & 18046 & 186 \\
\hline
\end{tabular}

a) Viscosity corresponding to $100 \%$ concentration of diluent was calculated by extrapolating the viscosity of each diluent in an aqueous solution. b) Oral disintegration time of tablets with $35 \%$ porosity after storage was compared.

tablet with larger pores has higher water penetration. ${ }^{11)}$

On the other hand, the viscosity of the diluent plays a role in tablet disintegration. The relationship between the viscosity of the diluent $\left(\eta_{c=100 \%}\right)$ and the oral disintegration time of tablets after storage is shown in Table 1. These tablets were comprised of different diluents and $20 \%$ of amorphous sucrose. Here, the viscosity corresponding to $100 \%$ diluent concentration $\left(\eta_{c=100 \%}\right)$ was calculated by extrapolating the viscosity of each diluent in an aqueous solution: the higher the diluent viscosity, the longer the oral disintegration time of tablets. From this result, it is thought that the formation of a viscous area inside the tablet, due to the penetration of a small amount of water, delayed the oral disintegration time.

For practical use, tablets with higher tensile strength and a faster oral disintegration time are desirable, and the relationship between oral disintegration time and the tensile strength of tablets after storage was therefore studied. It is well known that there is a general tendency toward prolonged disintegration time of tablets with increased tensile strength. ${ }^{12,13)}$ As shown in Fig. 3, although tablets had similar tensile strength, their disintegration time differed considerably depending on the diluent used. It is reported that patients can remove a tablet with a diameter of $8 \mathrm{~mm}$ and a hardness of $5 \mathrm{~kg}$ from a blister package and handle it easily. ${ }^{14)}$ The hardness corresponds to approximately $1 \mathrm{MPa}$ of tensile strength. The oral disintegration time was $10-30 \mathrm{~s}$ for tablets with a tensile strength of approximately $1 \mathrm{MPa}$, when erythritol, mannitol or xylitol was used as the diluent. On the other hand, the disintegration time was over $30 \mathrm{~s}$ when sorbitol or glucose was used. These results suggest that diluents with low viscosity are suitable for rapidly disintegrating oral tablet due to the fast water penetration.

The moisture absorption isotherms at $25^{\circ} \mathrm{C}$ for the diluents are shown in Fig. 4. The amount of moisture absorbed by xylitol, glucose or sorbitol increased with the increase in relative humidity, whereas erythritol or mannitol absorbed little water within the range of relative humidity examined (22-84\%). Among them, glucose and sorbitol had a tendency to absorb moisture at the relative humidity below $75 \%$, and, at the relative humidity of $84 \%$, the moisture content absorbed by these diluents was more than $5 \%$. Therefore, it can be easily expected that the tensile strength of the tablets containing these hygroscopic diluents decreases during storage under the high relative humidity conditions.

Considering these results of the viscosity and the hygroscopic property of the diluents, it is thought that the optimal diluents for rapidly disintegrating oral tablets prepared by the

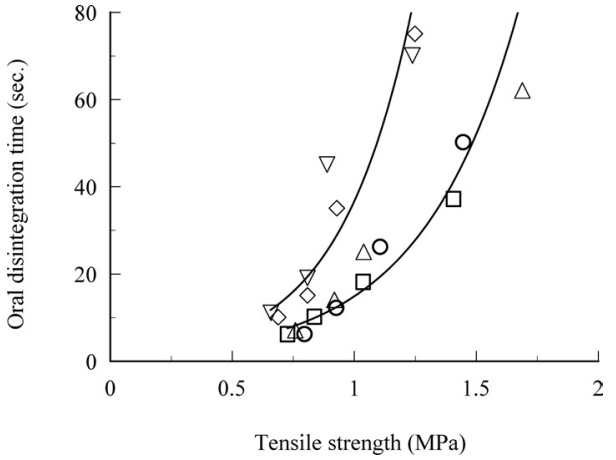

Fig. 3. Relationship between Oral Disintegration Time and Tensile Strength of Tablets

$\square$, erythritol; $\bigcirc$, mannitol; $\triangle$, xylitol; $\diamond$, glucose; $\nabla$, sorbitol. Oral disintegration time and tensile strength of tablets comprised of different diluents with $20 \%$ of amorphous sucrose after storage at $25^{\circ} \mathrm{C}$ under $34 \%$ relative humidity were measured.

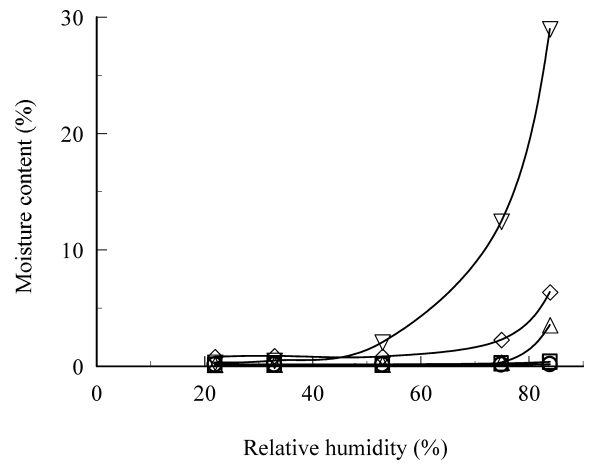

Fig. 4. Water Absorption Isotherms for Diluents at $25^{\circ} \mathrm{C}$

$\square$, erythritol; $\bigcirc$, mannitol; $\triangle$, xylitol; $\diamond$, glucose; $\nabla$, sorbitol.

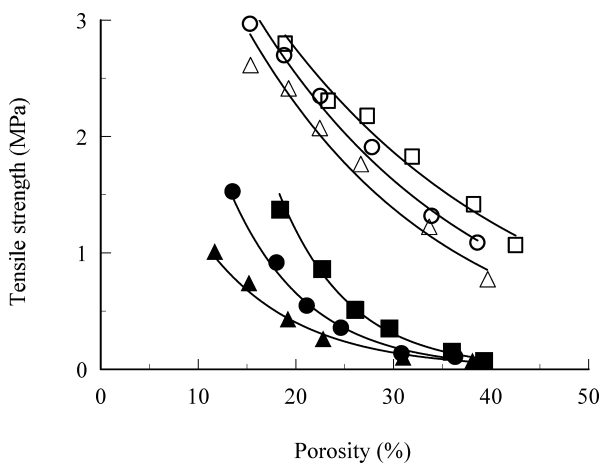

Fig. 5. Effect of Lactose Particle Size on the Increase in Tensile Strength of Lactose Tablets

$\boldsymbol{\square} \square, 75-100 \mu \mathrm{m} ; \bullet \bigcirc, 150-180 \mu \mathrm{m} ; \boldsymbol{\Delta} \Delta, 250-300 \mu \mathrm{m}$. Tensile strength of tablets comprised of different particle size of lactose with $20 \%$ of amorphous sucrose before (closed symbol) and after (open symbol) storage at $25^{\circ} \mathrm{C}$ under $34 \%$ relative humidity was measured.

CT method are erythritol, mannitol and xyritol.

The effect of diluent particle size on the characteristics of rapidly disintegrating oral tablets was investigated. In this study, $80 \%$ of crystal $\alpha$-lactose with a different particle size was compressed with $20 \%$ of amorphous sucrose. As shown in Fig. 5, the tensile strength of tablets increased as the size of primary $\alpha$-lactose particles decreased. This result suggests that an effective contact area between particles greatly affects the tensile strength of tablets. ${ }^{15-17)}$ The degree of tensile strength increase of these tablets during storage was similar, 
indicating that new internal contact points in the tablet, which attribute to the increase in tensile strength, were formed by amorphous sucrose crystallization.

In Vromans' study on spray-dried lactose particles composed of amorphous and crystalline forms, tablet disintegration depended on the fraction of the amorphous form, the size of the primary particles and the compaction pressure. The disintegration time increased with the size of the primary particles: for tablets of $15 \%$ amorphous lactose, the time increased with a primary particle size of more than $32 \mu \mathrm{m} .{ }^{18)}$ For this reason, they concluded that the viscous binding layer formed by amorphous part on the crystalline particles became thicker and hindered the penetration of water into the tablets when lactose with a larger particle size was used.

In contrast to their study, irrespective of the primary particle size of $\alpha$-lactose $(75-300 \mu \mathrm{m})$ in this study, the oral disintegration time of tablets after storage was almost independent of the primary particle size when tablets of similar porosity were compared (Table 2 ). A possible explanation of this result is that the amorphous sucrose had already transformed to the crystalline form during storage and water penetration was no longer hindered. Therefore, from the viewpoint of tensile strength, smaller particles are preferable for rapidly disintegrating oral tablets prepared by the CT method.

Effect of Active Drug Substance on Rapidly Disintegrating Oral Tablets Some active drug substances of different water solubility were formulated for this study. The properties of the active drug substances are shown in Table 3. The water solubility of the active drug substances varied from $0.006 \%$ to $997 \%(\mathrm{w} / \mathrm{v})$.
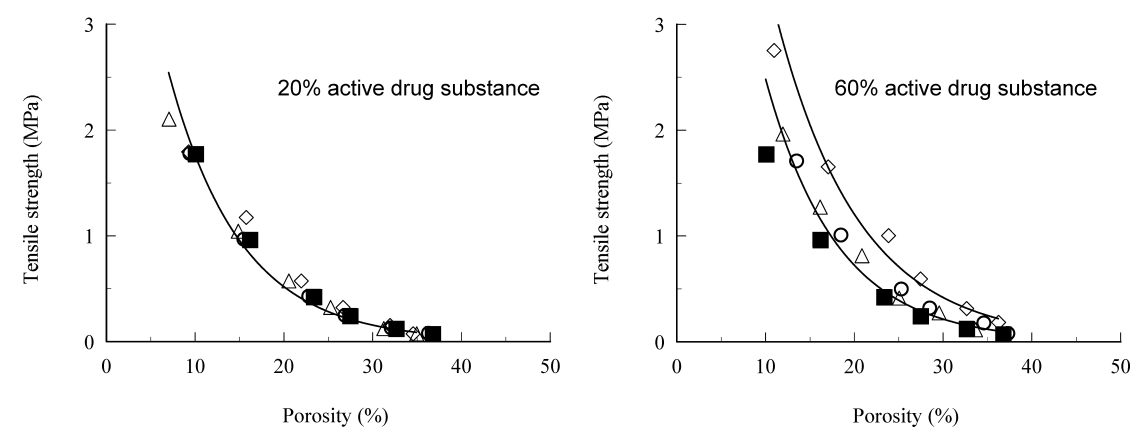

(b)
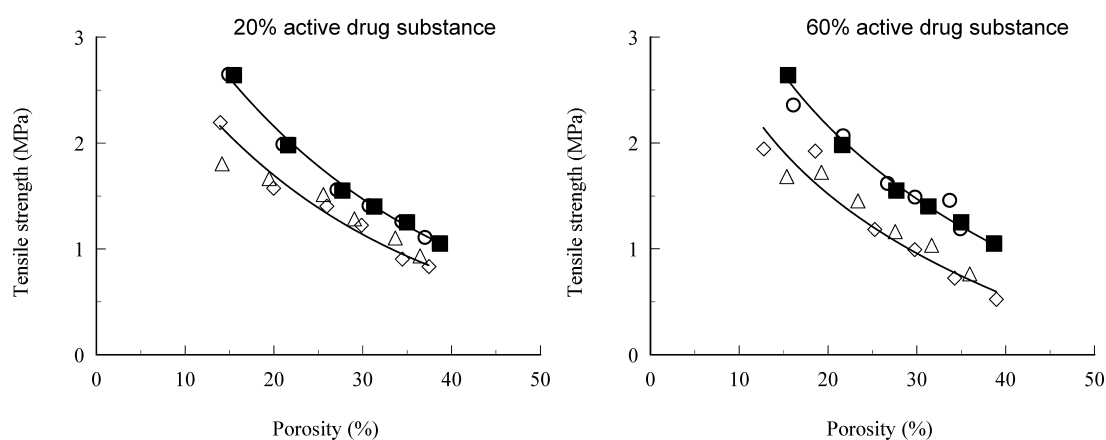

Fig. 6. Relationship between Tensile Strength and Porosity of Tablets

, without active drug substance; $\bigcirc, \mathrm{NA} ; \triangle$, DH; $\diamond$, BB. Tensile strength of tablets comprised of mannitol and $20 \%$ of amorphous sucrose with different ratio ( 20 or $60 \%$ ) of active drug substance before (a) and after (b) storage at $25^{\circ} \mathrm{C}$ under $34 \%$ relative humidity was measured.

Tablets comprised of mannitol and $20 \%$ of amorphous sucrose with $20 \%$ or $60 \%$ of active drug substance were prepared and stored at $25^{\circ} \mathrm{C}$ under $34 \%$ relative humidity. Figure 6 shows the relationship between the tensile strength and porosity of the tablets before and after storage. The increase in tensile strength during storage of tablets containing $60 \%$ of BB was low, probably due to insufficient formation of new

Table 2. Effect of Particle Size of $\alpha$-Lactose on Characteristics of Rapidly Disintegrating Oral Tablet

\begin{tabular}{cccc}
\hline \hline \multirow{2}{*}{$\begin{array}{c}\text { Particle size of } \\
\alpha \text {-lactose } \\
(\mu \mathrm{m})\end{array}$} & $\begin{array}{c}\text { Tensile strength } \\
(\mathrm{MPa})\end{array}$ & $\begin{array}{c}\text { Porosity } \\
(\%)\end{array}$ & $\begin{array}{c}\text { Oral disintegration time } \\
(\mathrm{s})\end{array}$ \\
\cline { 2 - 4 } & 1.41 & 38.3 & 10 \\
\hline $75-100$ & 1.82 & 32.0 & 15 \\
& 2.17 & 27.4 & 29 \\
$150-180$ & 1.08 & 38.7 & 7 \\
& 1.31 & 34.0 & 21 \\
& 1.90 & 27.9 & 6 \\
$250-300$ & 0.77 & 39.7 & 10 \\
& 1.22 & 33.7 & 30 \\
& 1.76 & 26.7 & \\
\end{tabular}

Table 3. Properties of Active Drug Substances

\begin{tabular}{cccc}
\hline \hline $\begin{array}{c}\text { Active drug } \\
\text { substance }\end{array}$ & $\begin{array}{c}\text { Particle size } \\
(\mu \mathrm{m})\end{array}$ & $\begin{array}{c}\text { True density } \\
\left(\mathrm{g} / \mathrm{cm}^{3}\right)\end{array}$ & $\begin{array}{c}\text { Solubility in water at } \\
37^{\circ} \mathrm{C}(\%)\end{array}$ \\
\hline NA & 40 & 1.44 & 997 \\
DH & 23 & 1.30 & 473 \\
BB & 6 & 1.38 & 0.006 \\
\hline
\end{tabular}

a) 


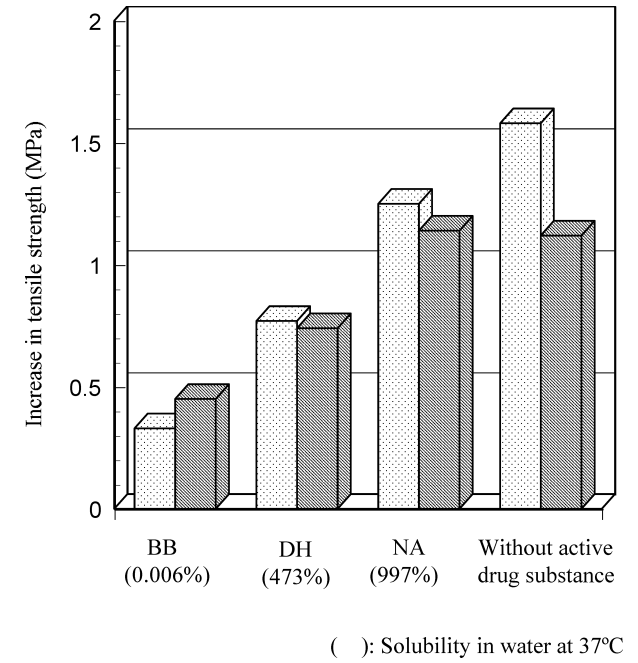

Fig. 7. Comparison of the Increase in Tensile Strength Containing $60 \%$ of Active Drug Substance

$$
\square, 20 \% \text { porosity; } \square, 35 \% \text { porosity. }
$$

solid bridges between drug particles with poor water solubility. On the other hand, tablets containing a highly water-soluble active drug substance (NA) showed a marked increase in tensile strength as did tablets without active drug substances.

In Fig. 7, the increase in tensile strength of tablets containing active drug substance during storage is summarized. Tablets containing $60 \%$ of active drug substances of different solubility were compared. The increase in tensile strength of either porosity $(20 \%$ or $35 \%)$ of the tablets was dependent on the solubility of active drug substances. The observed increase in tensile strength of tablets containing highly watersoluble active drug substances (NA) was larger than that of tablets containing extremely low water-soluble drugs (BB), e.g. the increase in tensile strength of NA tablets was four times larger than that of BB tablets when tablets of $20 \%$ porosity were compared.

Table 4 shows the effect of active drug substance addition on tablets of similar porosity. The tensile strength and disintegration time of tablets after storage were not appreciably affected by the addition of $20 \%$ active drug substance. At $60 \%$ of formulating ratio, active drug substances with lower water solubility resulted in lower tensile strength and longer oral disintegration time. Therefore, highly water-soluble active drug substances were more suitable for the formulation of rapidly disintegrating oral tablets prepared by the CT method.

Effect of Amorphous Sugar on Rapidly Disintegrating Oral Tablets In general, it is recognized that amorphous sugar produces tablets with higher tensile strength than crystalline sugar, due to its high bonding capacity. ${ }^{19,20)}$ Here, the effects of amorphous sucrose, lactose or maltose on the characteristics of rapidly disintegrating oral tablets were investigated. The amorphous sugars were prepared by freeze-drying and were confirmed as completely amorphous by X-ray diffraction measurement (Fig. 9). Amorphous mannitol was not obtained as a freeze-dried solid due to its low $\operatorname{Tg}\left(13^{\circ} \mathrm{C}\right) .^{21,22)}$ Tablets comprised of $80 \%$ of mannitol with $20 \%$ of amorphous sugar were stored at $25^{\circ} \mathrm{C}$ under different humidity conditions for $5 \mathrm{~d}$, because each amorphous sugar had a different $\mathrm{Tg}^{23)}$ Figure 8 shows the tensile strength of tablets be-
Table 4. Effect of Active Drug Substance Addition on Characteristics of Rapidly Disintegrating Oral Tablet

\begin{tabular}{ccccc}
\hline \hline \multirow{2}{*}{$\begin{array}{c}\text { Active drug } \\
\text { substance }\end{array}$} & $\begin{array}{c}\text { Formulating } \\
\text { ratio } \\
(\%)\end{array}$ & $\begin{array}{c}\text { Tensile strength } \\
(\mathrm{MPa})\end{array}$ & $\begin{array}{c}\text { Porosity } \\
(\%)\end{array}$ & $\begin{array}{c}\text { Oral disintegration time } \\
(\mathrm{s})\end{array}$ \\
\cline { 3 - 5 } & & 1.05 & 39 & 12 \\
None & - & 1.10 & 37 & 12 \\
NA & 20 & 1.18 & 35 & 12 \\
& 60 & 1.10 & 34 & 16 \\
DH & 20 & 0.76 & 36 & 30 \\
& 60 & 0.90 & 35 & 16 \\
BB & 20 & 0.52 & 39 & 58 \\
& 60 & &
\end{tabular}

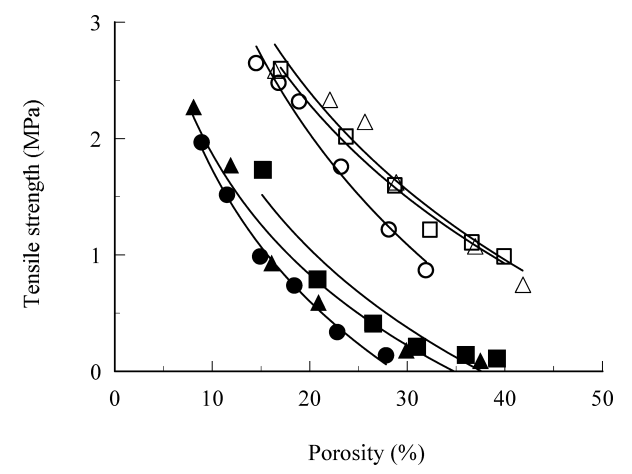

Fig. 8. Relationship between Tensile Strength and Porosity of Tablets

$\boldsymbol{\square} \square$, sucrose; $\bigcirc$, lactose; $\boldsymbol{\Delta} \triangle$, maltose. Tensile strength of tablets comprised of mannitol and different kinds of amorphous sugar before (closed symbol) and after (open symbol) storage at $25^{\circ} \mathrm{C}$ under different humidity conditions was measured.

fore and after storage. After storage, the increase in tensile strength was approximately $1 \mathrm{MPa}$ within the porosity range examined. The porosity of the tablets with $1 \mathrm{MPa}$ tensile strength was 30 to $40 \%$ and their oral disintegration time was $10-15 \mathrm{~s}$ irrespective of the amorphous sugar used.

In our previous paper, it had been confirmed by thermal analysis and powder X-ray diffraction measurement that the amorphous sucrose of the tablets comprised of mannitol and amorphous sucrose was crystallized during storage. ${ }^{6)}$ In this study, the change in crystal form of the tablets comprised of mannitol and amorphous sugar ( $\alpha$-lactose or maltose) during storage was investigated. Figure 9 shows the powder X-ray diffraction pattern of the tablets after storage, as well as the corresponding pattern of the tablets before storage. Mannitol and sugar (crystal and amorphous state) were also included for comparison. The diffraction peaks of the tablets before storage were identical to those of mannitol, since the amorphous sugars are amorphous form, and have no diffraction peaks. After storage, on the other hand, the characteristic peaks corresponding to the crystal $\alpha$-lactose or maltose appeared. This result indicates that the amorphous sugars crystallized during storage and formed internal contact points in the tablets as did amorphous sucrose.

Therefore, it is clear that various kinds of amorphous sugars can be used for rapidly disintegrating oral tablets prepared by the CT method.

\section{Conclusions}

The disintegration time of rapidly disintegrating oral tablets greatly depended on the diluent. The penetration of a 

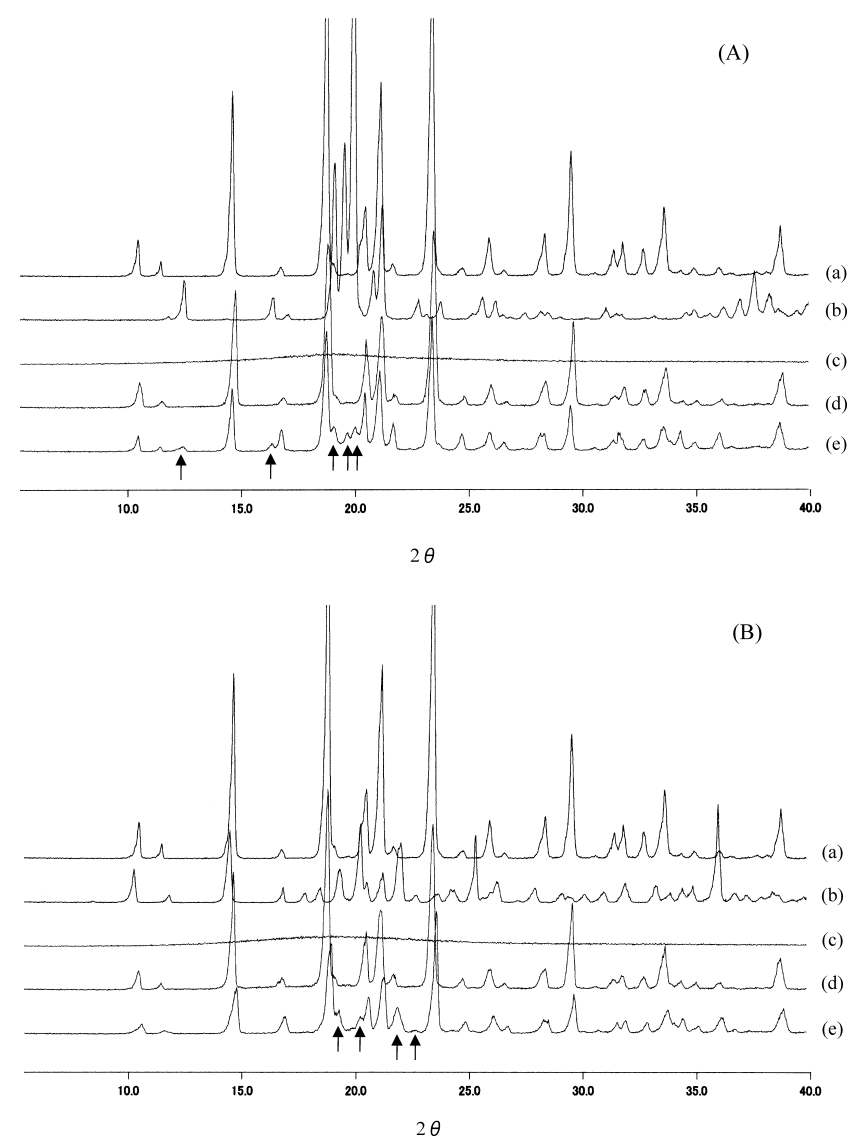

Fig. 9. X-Ray Diffraction Spectra of Tablets Comprised of Mannitol and Amorphous Sugar

(A) Tablets comprised of mannitol and amorphous lactose: (a) intact mannitol powder; (b) intact $\alpha$-lactose powder; (c) intact amorphous lactose powder; (d) tablet comprised of mannitol and amorphous lactose before storage; (e) tablet comprised of mannitol and amorphous lactose after storage.

(B) Tablets comprised of mannitol and amorphous maltose: (a) intact mannitol powder; (b) intact maltose powder; (c) intact amorphous maltose powder; (d) tablet comprised of mannitol and amorphous maltose before storage; (e) tablet comprised of mannitol and amorphous maltose after storage.

small amount of water in the mouth and the formation of a viscous area inside the tablet seemed to be related to the different disintegration times. On the other hand, the degree of tensile strength increase was hardly affected by the diluent. These results show that the optimal diluents for rapidly disin- tegrating oral tablets are erysritol, mannitol and xyritol. Furthermore, from the viewpoint of tensile strength increase during storage, smaller primary diluent particles were preferable. It was also found that highly water-soluble active drug substances were more suitable than low water-soluble active drug substances. It also became clear that amorphous lactose and maltose, in addition to sucrose, could be used in the preparation of rapidly disintegrating oral tablets by the CT method.

\section{References}

1) Bi Y. X., Sunada H., Yonezawa Y., Danjo K., Drug Dev. Ind. Pharm., 25, 571-581 (1999).

2) Bi Y. X., Yonezawa Y., Sunada H., J. Pharm. Sci., 88, 1004-1010 (1999).

3) Ishikawa T., Mukai B., Shiraishi S., Utoguchi N., Fujii M., Matsumoto M., Watanabe Y., Chem. Pharm. Bull., 49, 134-139 (2001).

4) Watanabe Y., Koizumi K., Zama Y., Kiriyama M., Matsumoto Y., Matsumoto M., Biol. Pharm. Bull., 18, 1308-1310 (1995).

5) Schiermeier S., Schmidt P. C., Eur. J. Pharm. Sci., 15, 295-305 (2002).

6) Sugimoto M., Matsubara K., Koida Y., Kobayashi M., Pharm. Dev Tech., 6, 487-493 (2001).

7) Hancock B. C., Zografi G., Pharm. Res., 10, 1262-1267 (1993)

8) Hancock B. C., Dalton C. R., Pharm. Dev. Tech., 4, 125-131 (1999).

9) Pesonen T., Paronen P., Ketolainen J., Int. J. Pharm., 57, 139-147 (1989).

10) Gissinger D., Stamm A., Drug Dev. Ind. Pharm., 6, 511-536 (1980).

11) Oshima T., Bi Y., Yonezawa Y., Sunada H., J. Pharm. Sci. Tech., Jpn., 63, 1-11 (2003).

12) Ondari C. O., Kean C. E., Rhodes C. T., Drug Devel. Ind. Pharm., 9, $1555-1572$ (1983)

13) Bowe K., Kuenzle C., Le A., Pharm. Res., 14, S-15 (1997).

14) Shu T., Suzuki H., Hironaka K., Ito K., Chem. Pharm. Bull., 50, 193 198 (2002).

15) Leuenberger H., Bonny J. D., Lerk C. F., Vromans H., Int. J. Pharm., 52, 91-100 (1989).

16) Takeuchi H., Yasuji T., Hino T., Yamamoto H., Kawashima Y., Pharm. Res., 16, 1193-1198 (1999).

17) Ross J. W. D., Pharm. Tech., September, 42-53 (1984).

18) Vromans H., Bolhuis G. K., Lerk C. F., Kussendrager K. D., Int. J. Pharm., 39, 201-206 (1987).

19) Sebhatu T., Alderborn G., Eur. J. Pharm. Sci., 8, 235-242 (1999).

20) Matsumoto K., Kimura T., Nakai Y., Yonemochi E., Oguchi T., Yamamoto K., J. Pharm. Sci. Tech., Jpn., 57, 1-7 (1997).

21) Kim A. I., Akers M. J., Nail S. L., J. Pharm. Sci., 87, 931-935 (1998).

22) Stubberud L., Forbes R. T., Int. J. Pharm., 163, 145-156 (1998)

23) Hancock B. C., Zografi G., Pharm. Res., 11, 471-477 (1994). 